\title{
Studies of Antioxidants and Xanthine Oxidase Inhibitory Potentials of Root and Aerial Parts of Medicinal Plant Capparis Spinosa L.
}

\author{
Abderrahmane Baghiani ${ }^{1, *}$, Djamila Ameni ${ }^{1}$, Sabah Boumerfeg $^{2}$, Moufida Adjadj $^{1}$, Meriem Djarmouni $^{1}$, \\ Noureddine Charef ${ }^{1}$, Seddik Khennouf ${ }^{3}$, Lekhmici Arrar ${ }^{1}$ \\ ${ }^{1}$ Laboratory of Applied Biochemistry, Department of Biochemistry. Faculty of Natural and Life Sciences, University Ferhat Abbas, Setif \\ 19000, Algeria \\ ${ }^{2}$ Department of Biology, University of Bordj Bou Ariridj \\ ${ }^{3}$ Laboratory of Phytotherapy Applied to Chronic Diseases, Department of Animal Biology and Physiology, Faculty of Natural and Life
}

Sciences, University Ferhat Abbas, Setif 19000, Algeria

\begin{abstract}
Capparis spinosa aerial part and root extracts were prepared using solvents of varying polarity. Results showed that ethyl acetate extract (EAE) of the aerial part contains the highest concentration of phenolic compounds and flavonoids followed by the chloroform extract (CHE) of roots. The enzymatic methods were realised by the production of uric acid and reduction of cytochrome c. Result showed that all plant extracts were effective either in inhibiting the activity of XO or Cyt C. The IC50 ranges from $0.0226 \pm 0.00019$ to $4.32 \pm 0.15 \mathrm{~g} / \mathrm{l}$. The non enzymatic methods were conducted using in vitro techniques: In DPPH test, the radical scavenging activity for the root and aerial part extracts decreased in the following order $\mathrm{CHE}>\mathrm{EAE}>\mathrm{CE}$ and $\mathrm{EAE}>\mathrm{CE}>\mathrm{CHE}$, respectively. In general the aerial part extracts had an antioxidant activity through $\beta$-carotene-linoleate model system and ferric reducing ability greater than that of root part. In conclusion, Capparis spinosa appears to be a valuable plant and could be used to treat conditions where inhibition of XOR and free-radicals scavenging action are warranted.
\end{abstract}

Keywords Capparis Spinosa L., Reducing Power, Superoxide Anion Radicals, Phenolic Compounds, Xanthine Oxidase Cytochrome C, DPPH and ß-Carotene-Linoleate

\section{Introduction}

Oxidative stress is a general term used to identify the level of oxidative damage in a cell, tissue, or organ, caused by the oxygen and its reactive oxygen species (ROS) such as hydrogen peroxide $\left(\mathrm{H}_{2} \mathrm{O}_{2}\right)$ or free radicals such as superoxide ions $\left(\mathrm{O}_{2}^{-}\right)$and hydroxyl radicals $\left(\mathrm{OH}^{*}\right)[1]$. ROS production can induce DNA damage, protein carbonylation, and lipid peroxidation, leading to a variety of chronic health problems, such as cancer, aging, Parkinson's disease, Alzheimer's disease and amyotrophic lateral sclerosis[2][3]. Antioxidants are vital substances which possess the ability to protect the body from damage caused by free radical induced oxidative stress. The antioxidants could attenuate the oxidative damage of a tissue indirectly by enhancing natural defences of cell and/or directly by scavenging the free radical species[4]. There are two categories of antioxidants: namely synthetic and natural ones. It has been discovered that the synthetic

* Corresponding author:

baghiani@yahoo.fr (Abderrahmane Baghiani)

Published online at http://journal.sapub.org/ajmms

Copyright (C) 2012 Scientific \& Academic Publishing. All Rights Reserved antioxidant have some side effects[5]. Therefore, there is an increasing interest in natural antioxidants present in medicinal and dietary plants, which might help prevent oxidative damage[6]. Capparis spinosa L. (Capparaceae) is a common perennial shrub in the Mediterranean regions, growing both wild and cultivated, with medicinal and aromatic properties. In the north of Algeria, Capparis spinosa L. is used for treatment of asthma and rheumatism. Immature flower buds, unripe fruits and shoots are consumed as foods or condiments; flower buds, fruits, seeds, shoots and bark of roots were traditionally used for pharmacological purposes, especially for rheumatism[7]. The seeds can be used to relieve toothache[8], the fruits and the root have been used in gout and also as astringents[9]. Further C. spinosa considered as a very important source of medicine for antifungal[10], anti-inflammatory[11], antidiabetic, antihyperlipidemic[12], anti hypertensive, poultice[13], antileishmania[14], antihepatotoxic[15] and Antiallergic activities[16]. In the present study, the antioxidant activity of extracts from the root and aerial parts of C. spinosa was assayed through various in vitro Methods.

\section{Materials and Methods}




\subsection{Extraction of Phenolic Compounds}

The extraction procedure for phenolic compounds was conducted as described by Markham (1982)[17]. The dried plant material $(100 \mathrm{~g})$ was ground to a coarse powder and soaked in $1000 \mathrm{ml}$ of methanol-water solution $(85: 15 \mathrm{v} / \mathrm{v})$. The solution was agitated and kept for $24 \mathrm{~h}$ in the dark at room temperature. The suspension was filtered through a Buchner funnel and concentrated under reduced pressure on a rotary evaporator to give crude extract (CE). The aqueous solution was extracted with hexane several times to eliminate lipids. The water fraction successively extracted with chloroform and ethyl acetate. Each fraction was evaporated to dryness under reduced pressure to give chloroform (CHE) and ethyl acetate (EAE) extracts. The extracts were stored at $-20{ }^{\circ} \mathrm{C}$ until use.

\subsection{Determination of Total Polyphenol Contents}

The total phenol content was determined by the Folin-Ciocalteu method as described by Cliffe et al (1994)[18] with slight modification. In brief, $0.1 \mathrm{ml}$ of Caparis spinosa extracts were well mixed with $2.5 \mathrm{ml}$ of distilled water and $0.5 \mathrm{ml}$ of the Folin-Ciocalteu stock reagent, after $5 \mathrm{~min} 1.0$ $\mathrm{ml}$ of $\mathrm{Na}_{2} \mathrm{CO}_{3}$ reagent $(20 \%)$ was added to the mixture. They were then incubated at room temperature for $1 \mathrm{~h}$. The mixture absorbance was spectrophotometrically measured at wavelength $760 \mathrm{~nm}$. The amount of total polyphenols in different extracts was determined from a standard curve of Gallic acid then the results were expressed in milligrams of gallic acid equivalents per gram of $C$. spinosa extracts.

\subsection{Determination of Flavonoid Contents}

Flavonoids were quantified using aluminium chloride reagent $\left(\mathrm{AlCl}_{3}\right)$ [19]. Flavonoids were measured as quercetin equivalents. One $\mathrm{ml}$ of CSAE and CSRE samples were dissolved in methanol, $1 \mathrm{ml}$ of $\mathrm{AlCl}_{3}(2 \%)$ in methanol was added, after incubation for $10 \mathrm{~min}$, the absorbance was measured at $430 \mathrm{~nm}$.

\subsection{Purification of Milk Bovine Xanthine Oxidoreductase}

XOR was purified from bovine milk, in the presence of 10 $\mathrm{mM}$ of dithiothrietol, by ammonium sulphate fractionation, followed by affinity chromatography on heparin-agarose, as described for human, bovine, sheep and camel XOR[20],[21]. The XOR concentration was determined from the UV-visible spectrum by using an absorption coefficient of $36000 \mathrm{M}^{-1}$ $\mathrm{cm}^{-1}$ at $450 \mathrm{~nm}$. The purity of enzyme was assessed on protein/flavone ratio $\left(\mathrm{PFR}=\mathrm{A}_{280} / \mathrm{A}_{450}\right)$ [22] and sodium dodecyl sulphate polyacrylamide gel electrophoresis (SDS-PAGE) $(10 \%)[23]$. The activity of XOR was spectrophotometrically determined by measuring the production of uric acid from xanthine $(100 \mu \mathrm{M}$, final concentration) at $295 \mathrm{~nm}$ using an absorption coefficient of $9600 \mathrm{M}^{-1} \mathrm{~cm}^{-1}$ 24]. Assays were performed at room temperature in air-saturated $50 \mathrm{mM}$ phosphate buffer, $\mathrm{pH}$ 7.4, supplemented with $0.1 \mathrm{Mm}$ EDTA.

\subsection{Effects of Aerial and Root Parts Extracts of C. spinosa on XO Activity}

The effects of different extracts of C. spinosa on XO activity were determined spectrophotometrically by measuring the uric acid production at $295 \mathrm{~nm}$ [25]. The enzyme assay was performed in the presence of $100 \mu \mathrm{M}$ of xanthine dissolved in phosphate buffer $(50 \mathrm{mM}, \mathrm{pH} 7.4)$, containing $0.1 \mathrm{mM}$ EDTA, supplemented with various amount of plant extracts. The reaction was initiated by the addition of $\mathrm{XO}$ (1176 $\mathrm{\eta mole} / \mathrm{min} / \mathrm{mg}$ of enzyme). Allopurinol was used as a positive standard.

\subsection{Effects of Aerial and Root Parts Extracts of C. Spinosa on Superoxide Anions Generation by XO}

The XO superoxide anions generation can be measured by following the cytochrome $\mathrm{c}$ reduction at $550 \mathrm{~nm}\left(\varepsilon_{\mathrm{Cytc}}=\right.$ $21100 \mathrm{M}^{-1} \mathrm{~cm}^{-1}$ )[26]. The reaction mixture containing: 50 $\mathrm{mM}$ phosphate buffer (pH 7.4), $0.1 \mathrm{mM}$ EDTA, $100 \mu \mathrm{M}$ xanthine, $25 \mu \mathrm{M}$ cytochrome $\mathrm{c}$ and various concentrations of plant extracts. Reaction was started by the addition of XO. The results were expressed as percentage inhibition of cytochrome $\mathrm{c}$ reduction.

\subsection{Antioxidant Assay Using B-Carotene-Linoleate Model System}

In this assay, antioxidant capacity is determined by measuring the inhibition of the volatile organic compounds and the conjugated diene hydroperoxides arising from linoleic acid oxidation[27]. Emulsion $(2.5 \mathrm{ml})$ containing $\beta$-carotene, linoleic acid and Tween-40 (polyoxyethylene sorbitan monopalmitate), was added to $0.35 \mathrm{ml}$ of $C$. spinosa extracts, then incubated for $48 \mathrm{~h}$ at room temperature. The same procedure was repeated with synthetic antioxidant BHT as positive control, and blanks $\left(\mathrm{MeOH}\right.$ and $\left.\mathrm{H}_{2} \mathrm{O}\right)$. The absorbances of the mixtures were measured at $490 \mathrm{~nm}$ after; $0,1,2,4,6,24$ and 48 hour. The antioxidant activity (AA) of the extracts was evaluated as a percentage of bleaching of $\beta$-carotene: $\mathrm{AA}=\left[\left(\mathrm{A}_{0-} \mathrm{A}_{\mathrm{t}}\right)-\left(\grave{\mathrm{A}}_{0}-\grave{\mathrm{A}}_{\mathrm{t}}\right) /\left(\mathrm{A}_{0-} \mathrm{A}_{\mathrm{t}}\right)\right]^{*} 100$

$A_{0}$ : measured absorbance value of control at zero time; $A_{t}$ : measured absorbance value of control after 24 hours; $\grave{A}_{0}$ : measured absorbance value of sample at zero time; $\dot{A}_{t}$ : measured absorbance value of sample after 24 hours. Antioxidative capacities of the extracts were compared with those of BHT and blank.

\subsection{Free Radical Scavenging Activity Using 1, 1-Diphenyl-2-Picryl Hydrazyl (DPPH) Radical}

The free radical scavenging activities of $C$. spinosa extracts were measured by decrease in the absorbance of methanol solution of DPPH[28]. An equal volume of each extracts with different concentrations were added to methanolic solution of DPPH and shaken vigorously at room temperature. After $30 \mathrm{~min}$, the absorbance was recorded at $517 \mathrm{~nm}$. Radical scavenging activity was expressed as the inhibition percentage and was calculated using the following formula $\mathrm{I} \%=\left(\mathrm{A}_{\text {blank }}-\mathrm{A}_{\text {sample }} / \mathrm{A}_{\text {blank }}\right) \times 100$ 


\subsection{Determination of Ferric Reducing Ability of Plasma (FRAP) as Measure of Antioxidant Power "the FRAP Assay"}

Antioxidant activity of different extracts of $C$. spinosa was measuring colorimetrically using the ferric reducing ability of plasma (FRAP) assay[29] following the modification by Pulido et al., (2000)[30]. FRAP assay was determined based on the reduction of $\mathrm{Fe}^{+3}-\mathrm{TPTZ}$ to a blue coloured $\mathrm{Fe}^{+2}$-TPTZ. Briefly, the FRAP reagent was prepared from sodium acetate buffer (300 mM, pH 3.6), $10 \mathrm{mM}$ TPTZ solution in $40 \mathrm{mM}$ $\mathrm{HCl}$ and $2.5 \mathrm{ml} \mathrm{FeCl}$ solution $(20 \mathrm{mM})$. The FRAP reagent was prepared fresh daily and was warmed to $37^{\circ} \mathrm{C}$ before using. FRAP reagent $(900 \mu \mathrm{l})$ was pipetted into test tubes. A total of $30 \mu \mathrm{l}$ of sample and $300 \mu \mathrm{l}$ of bidistilled water was then added to the same test tubes, and incubated at $37^{\circ} \mathrm{C}$ for $30 \mathrm{~min}$ in the dark condition. Gallic acid, ascorbic acid, rutin and quercetine were used as the standard. Reading of the colored product was then taken at $595 \mathrm{~nm}$. The standard curve was using iron (II) sulphate solution $(0-2000 \mu \mathrm{M})$, and the reducing power were expressed as equivalent concentration (EC1). This parameter was defined as the concentration of antioxidant having a ferric reducing ability equivalent to that $1 \mathrm{mM} \mathrm{FeSO}, 7 \mathrm{H}_{2} \mathrm{O}$. Quercetin, rutin, gallic acid and ascorbic acid were used as standards. All of the measurements were taken in duplicate and the mean values were calculated.

\section{Results and Discussion}

\subsection{Determination of Total Phenolics and Flavonoid Contents}

Phenolic compounds are commonly found in both edible and non-edible plants, and they have been reported to have multiple biological effects, including antioxidant activity[31]. Table 1 presents the yields and the amount of phenolic and flavonoid compounds in different extracts of aerial parts and root of $C$. spinosa. Total phenolic contents were expressed as mg gallic acid equivalents per gram dry weight (mg GA-Eq/g) and total flavonoids contents as mg quercetin equivalents per gram dry weight ( $\mathrm{mg} \mathrm{Q}-\mathrm{Eq} / \mathrm{g}$ ).

In roots material, the chloroform extract (CHE) presents the highest amount of phenolic compounds $(58.66 \pm 2.14)$ followed by ethyl acetate extract (EAE) $(45.96 \pm 5.86)$ and crud extract (CE) $(4.49 \pm 1.53)$. In aerial part extracts, the ethyl acetate extract (EAE) contained the highest concentration of phenolic compounds $(87.48 \pm 2.04)$ followed by the chloroform extract (CHE) $(25.01 \pm 1.64)$ and the crud extract (CE) $(14.86 \pm 0.62)$, respectively. Flavonoids contents were in the following order: EAE $>\mathrm{CHE}>\mathrm{CE}$ for both root and aerial part extracts. Except the chloroform root extract which contains flavonoid concentration higher than that of the same extract in the aerial part. In general the total phenolics and flavonoids compounds were found in higher concentration in aerial part than in root extract (Table 1).

\subsection{Xanthine Oxidase Purification}

XOR was purified from bovine milk following the method described by[32] modified by Baghiani et al[21]. This method allowed obtaining the crud extract of XOR. The purity of enzyme was assessed by using protein/flavin ratio $\left(\mathrm{PFR}=\mathrm{A}_{280} / \mathrm{A}_{450}\right)[22]$ and sodium dodecyl sulphate polyacrylamide gel electrophoresis (SDS-PAGE) (10\%)[23]. Bovine milk was found to yield around $23.21 \mathrm{mg}$ XOR protein per litre milk, comparable to the amounts reported by Baghiani et $a l[20],[21]$, the obtained enzyme was largely (more than $90 \%$ ) under the oxidase form. The purified bovine $\mathrm{XO}$ showed an ultraviolet/visible spectrum with three peaks at $280,330,450 \mathrm{~nm}$ with $\mathrm{A}_{280} / \mathrm{A}_{450}$ (protein to flavin, PFR) ratio of 5.15 indicating a high degree of purity[22]. This results are comparables with those found by Abadeh et al, (1992)[33] (5.13) and Benboubetra et al (2004)[34] (5.34). Run on SDS/PAGE, purified enzyme showed one major band of approximately $\mathrm{M}_{\mathrm{r}} 150 \mathrm{KDa}$. This is analogous to the well-studies Camel XOR enzyme[20].

\subsection{Effects of Aerial and Root Parts Extracts of C. spinosa on XO Activity}

XOR catalyses the hydroxylation of hypoxanthine to xanthine and xanthine to uric acid yielded superoxide anion and hydrogen peroxide. The reactive oxygen species producing by $\mathrm{XO}$, can modify the structure and function of macromolecules including proteins, lipids, carbohydrates, and nucleic acids[35]. The inhibitory effect of different plant extracts on XO activity were determined spectrophotometrically by measuring uric acid production at $295 \mathrm{~nm}$. All the plant extracts inhibited the activity of xanthine oxidase in a concentration dependent manner (Fig. 1), with an $\mathrm{IC}_{50}$ $(\mathrm{mg} / \mathrm{ml})$ value of $(0.32 \pm 0.015,0.0226 \pm 0.00019),(0.363 \pm$ $0.0085,0.09 \pm 0.0883)$ and $(4.32 \pm 0.15,1.35 \pm 0.0154)$ for CHE, EAE and CE for root and aerial parts of C. spinosa L., respectively. The effects of aerial part extracts were higher than those of root part extracts (Fig. 1).

Table 1. Total phenolic and flavonoid contents of Capparis spinosa L. root and aerial parts extracts

\begin{tabular}{|c|c|c|c|c|c|c|}
\hline \multirow{2}{*}{ Extracts } & \multicolumn{2}{|c|}{ \%yield(w/w) } & \multicolumn{2}{c|}{$\begin{array}{c}\text { Total phenolic content } \\
\text { (mg GA-Eq/g) }\end{array}$} & \multicolumn{2}{c|}{$\begin{array}{c}\text { Total flavonoids } \\
\text { (mg Q-Eq/g) }\end{array}$} \\
\cline { 2 - 7 } & Root & Aerial Part & Root & Aerial Part & Root & Aerial Part \\
\hline CE & $12.55 \pm 0.72$ & $6.65 \pm 1.34$ & $4.49 \pm 1.53$ & $14.86 \pm 0.62$ & $0.25 \pm 0.12$ & $23.50 \pm 0.76$ \\
\hline CHE & $0.30 \pm 0.041$ & $0.38 \pm 0.091$ & $58.66 \pm 2.14$ & $25.01 \pm 1.64$ & $2.16 \pm 0.71$ & $31.37 \pm 4.27$ \\
\hline EAE & $0.31 \pm 0.022$ & $0.38 \pm 0.058$ & $45.96 \pm 5.86$ & $87.48 \pm 2.04$ & $2.12 \pm 0.55$ & $298.33 \pm 1.70$ \\
\hline
\end{tabular}

Values are expressed as mean $\pm \mathrm{SD}(\mathrm{n}=6)$ 

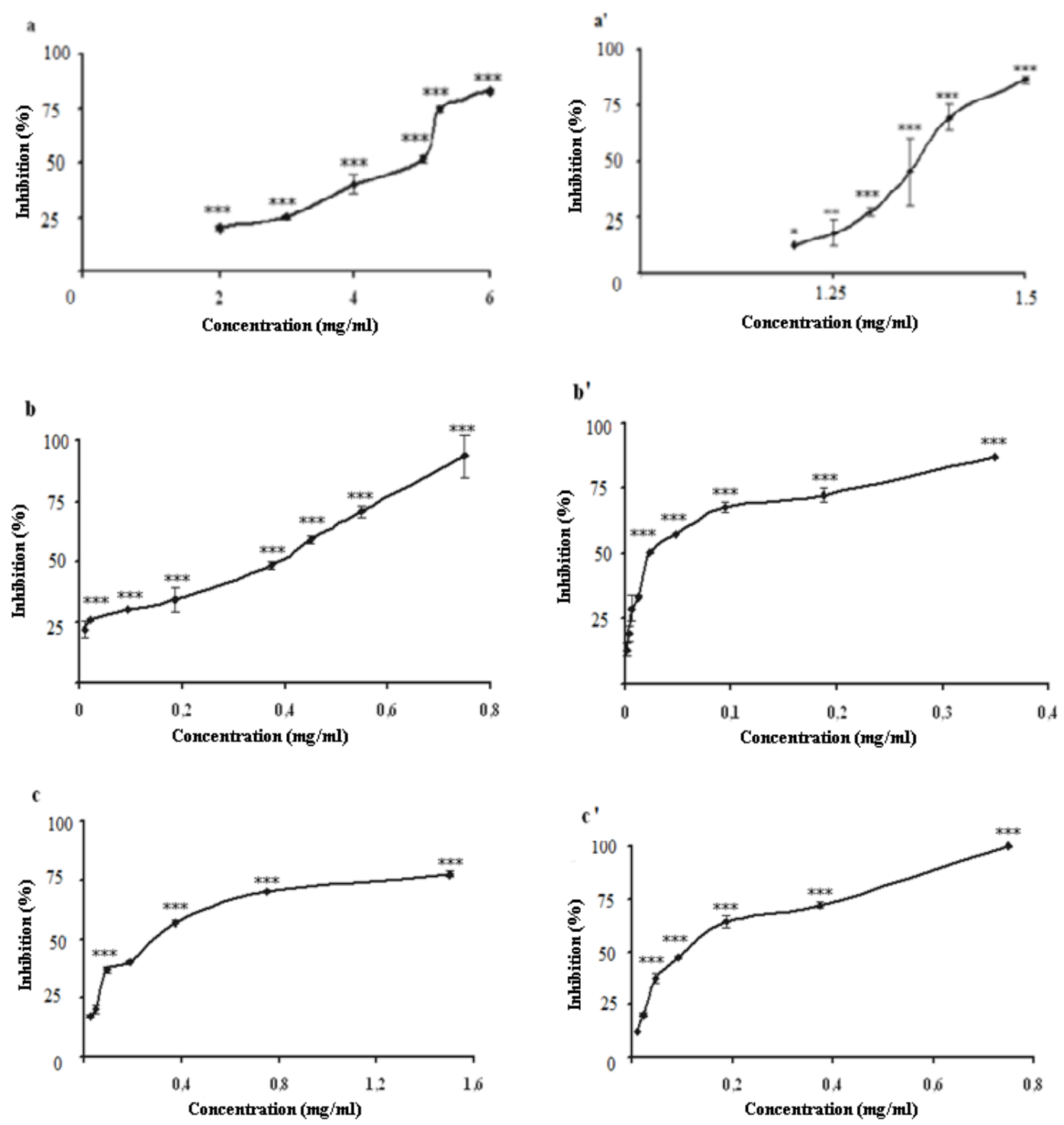

Figure 1. Inhibitory actions of root and aerial parts extracts of C. spinosa on xanthine oxidase activity. Results are expressed as percentage of control where no inhibitor was added. Each value is represented as mean \pm S.D $(n=3)$. Curve a, a' represent crud extracts; b, b': chloroform extracts; c,c': ethyl acetate extracts. $(* * * p \leq 0.01 ; * \mathrm{*} \leq 0.01 ; * \mathrm{p} \leq 0.05)$

Flavonoids can contribute to a decrease in oxidative stress via inhibition or activation of key regulating enzymes[36] such as xanthine oxidase, phospholipase and nitric oxide synthase. The inhibition of the enzymes by some flavonoids could be due to a reaction of the flavonoid with free radicals generated at the active site of the enzymes. The antioxidant activity of flavonoids is due for both the presence of aromatic $\mathrm{OH}$ groups and their number per molecule who are considered to play a pivotal role[37]. From the results of Montoro and her collaborators (2005)[38], it appears that, for the inhibition of $\mathrm{XO}$ activity by flavonoids, the hydroxyl groups at C-5 and C-7 and the 2,3-double bond are important: between flavonols, quercetins 3 and 6 and myricetins 11 and 12 were the most active, while myricetin derivatives 13-15, without the hydroxyl group at C-5, were less active.

\subsection{Effects of Aerial and Root Parts Extracts of}

\section{C. spinosa on Superoxide Anions Generation by XO System}

The superoxide anion generated by xanthine/xanthine oxidase system can reduce the cytochrome $\mathrm{c}^{+3}$ to cytochrome $\mathrm{c}^{+2[39]}$. The scavenger ability of different extracts of $C$. spinosa on superoxide anions radicals produced by xanthine oxidase (XO) can be measured by following the cytochrome c reduction at $550 \mathrm{~nm}[26]$. All the extracts were able to reduce the cytochrome $\mathrm{c}^{+3}$ in concentration-dependent manner (Fig. 2) $(\mathrm{p}<0.001)$. The aerial part extracts have a potent scavenging activity of superoxide anion radical higher than those of the root part extracts $(\mathrm{p}<0.001)$, with an $\mathrm{IC}_{50}$ $(\mathrm{mg} / \mathrm{ml})$ value of $(\mathrm{CE}=1.08 \pm 0.014,2.58 \pm 0.021),(\mathrm{CHE}=$ $0.58 \pm 0.006,1.17 \pm 0.016)$ and $(\mathrm{EAE}=0.62 \pm 0.0016,1.30 \pm$ 0.0076 respectively). The $C$. spinosa extracts has an inhibitory effect on XO activity, so their scavenger effects on superoxide anion is due to dual effect of the extracts on XO 
activity and superoxide anion scavenging. Structure-activity relationships of flavonoids in the inhibition of $\mathrm{XO}$ and in the scavenging of superoxide anion appeared similar[38]. Structural differences between flavonols, flavones, flavanones, and dihydroflavonols influenced the inhibitory effect on $\mathrm{XO}$ and superoxide anion. The insaturation in the $\mathrm{C}$ ring and the free hydroxyl group at C-7 enhanced the activity.

\subsection{Free Radical Scavenging Activity Using 1, 1-Diphenyl-2-Picryl Hydrazyl (DPPH) Radical}

DPPH radicals are widely used in the model system to investigate the scavenging activities of several natural compounds. When DPPH radical is scavenged, the colour of the reaction mixture changed from purple to yellow with decreasing of absorbance at wavelength $517 \mathrm{~nm}$. The free radical scavenging activity of the aerial and root parts extracts of C. spinosa were tested through DPPH method and the results are presented in the (Fig. 3 a,b). In the present study all the extracts of $C$. spinosa were able to decolourise $\mathrm{DPPH}$. The radical scavenging activity for the root and
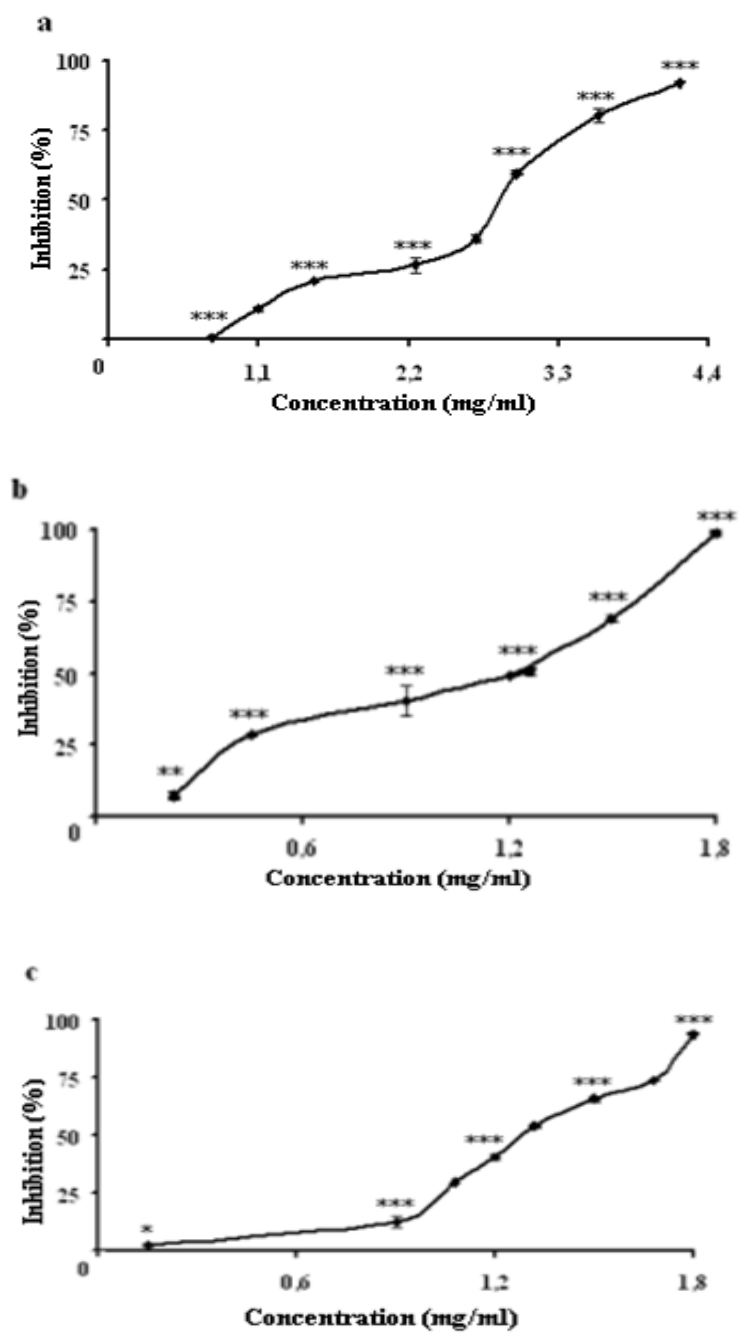

aerial plant extracts decreased in the following order $\mathrm{CHE}>$ $\mathrm{EAE}>\mathrm{CE}$ and $\mathrm{EAE}>\mathrm{CE}>\mathrm{CHE}$, respectively. It has been found that the highest radical scavenging activity was showed for the aerial part extracts. Therefore, the antioxidant effects of $\mathrm{CE}, \mathrm{CHE}$ and $\mathrm{EAE}$ of aerial part were greater than those of the same extracts in root part with 34, 3 and 43 folds, respectively. This may be related to the high amount of flavonoid and phenolic compounds in these plant extracts.
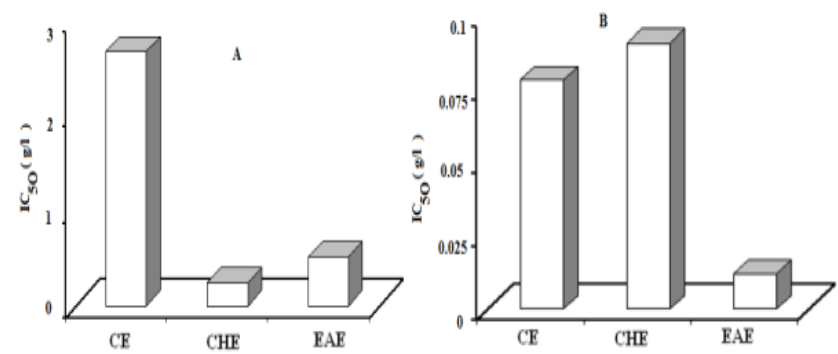

Figure 3. $\mathrm{IC}_{50}$ values of plant extracts for free radical scavenging activity by $\mathrm{DPPH}$ method. Lower $\mathrm{IC}_{50}$ value indicates higher antioxidant activity. (A): root part extracts, (B): aerial part extracts. CE; crud extract, CHE; chloroform extract, EAE; ethyl acetate extract
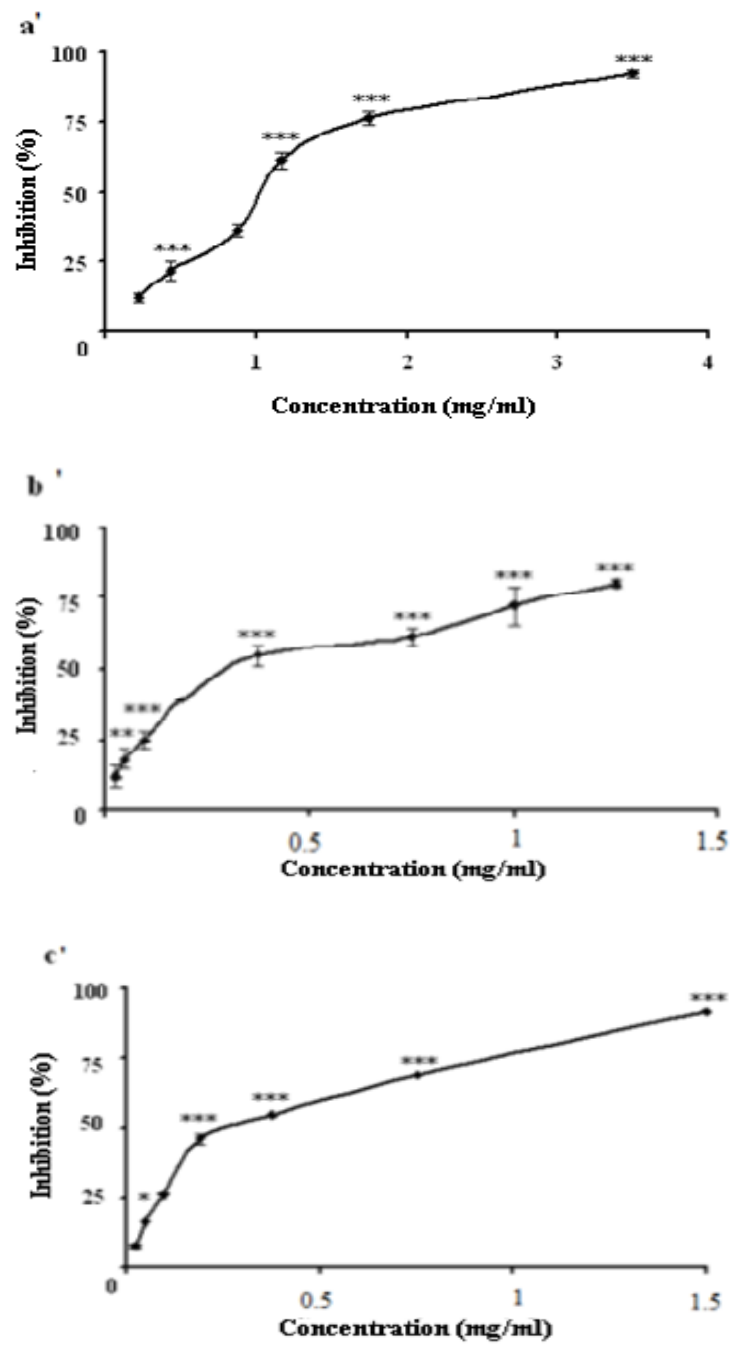

Figure 2. Inhibition of superoxide anion radicals generating from xanthine/xanthine oxidase system by the root and aerial parts extracts, respectively. a,a'; crud extract, b, b'; chloroform extract, c, c' ethyl acetate extract. (***p $\left.\leq 0.01 ; * * \mathrm{p} \leq 0.01 ; *^{*} \mathrm{p} \leq 0.05\right)$ 
Previous chemical studies on C. spinosa have shown the presence of alkaloids, lipids, polyphenols, flavonoids, indole and aliphatic glucosinolates[40]. The high scavenging activity of aerial part extracts may be due to hydroxyl groups existing in the phenolic compounds. Phenolic compounds are called high-level antioxidants because of their ability to scavenge free radicals and active oxygen species such as singlet oxygen, superoxide free radicals and hydroxyl radicals[41].

\subsection{Antioxidant Assay Using $\beta$-Carotene-Linoleate Model System}

In the $\beta$-carotene bleaching assay, linoleic acid produces hydroperoxides as free radicals during incubation. The presence of antioxidants in the extracts will minimise the oxidation of $\beta$-carotene by hydroperoxides. Hydroperoxides formed in this system will be neutralized by the antioxidants from the extracts. The antioxidant activity through $\beta$-carotene-linoleate model system of C. spinosa extracts and butylated hydroxytoluene (BHT) is presented in. Both root and aerial parts extracts gave a high inhibition and exhibited varying degrees of antioxidant capacity when compared BHT (Fig 4). EAE, CHE and CE showed $82.84 \%, 77.38 \%$ and $23.51 \%$ respectively, in root part extract. In the aerial part extract, the antioxidant activity decreases in the following order $\mathrm{CHE}>\mathrm{CE}>\mathrm{EAE}$. Except for the ethyl acetate root extract which exhibited a power antioxidant effect $(82,84 \%)$ all the aerial part extract had an antioxidant activity higher than those of root part extracts (Fig 4).

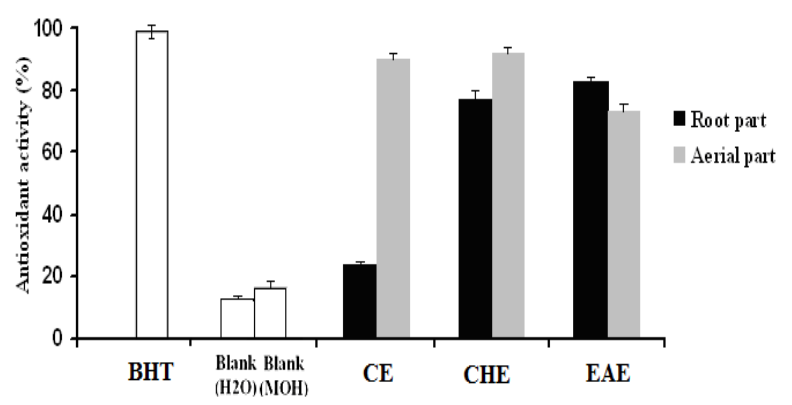

Figure 4. Comparison of the antioxidant activity of root and aerial parts extracts of C. spinosa measured, BHT and blanks $\left(\mathrm{H}_{2} \mathrm{O}\right.$ and Methanol) by using $\beta$-carotene- linoleate assay (Percentage $(\%)$ inhibition of the linoleic acid oxidation) after 24 hours. Results are means of three different experiments

The difference in antioxidant activities of the root and aerial parts extracts of $C$. spinosa might be attributed to a difference in total phenolic content. Several studies showed a correlation between antioxidant activity and phenolic content[42],[43]. However, based on B-carotene bleaching assay, the study showed no correlation between antioxidant activity and phenolic content for both parts extracts. Our finding is in agreement with Othman et al (2007)[44]. who reported that cocoa beans extract of Ghana and Ivory Coast with the lowest phenolic content, exhibited the highest antioxidant activity.
Since the chemical composition and structures of active extract components are important factors governing the efficacy of natural antioxidants, the antioxidant activity of an extract could not be explained on the basis of their phenolic content, which also needs their characterization[45]. A high antioxidant activity could also be due to other compounds besides phenolics which are soluble in different solvents.

\subsection{Determination of Ferric Reducing Ability of Plasma (FRAP) as Measure of Antioxidant Power "the FRAP Assay"}

Several methods have been developed to evaluate the total antioxidant activity of fruits or other plants and animal tissues. In the present studies, the ferric reducing antioxidant power (FRAP) assay, that giving an indication of the reducing ability of the plant extract, was used to evaluate the antioxidant activity of different extracts of $C$. spinosa. Results showed that the reduction kinetics of TPTZ- $\mathrm{Fe}^{+3}$ to TPTZ- $\mathrm{Fe}^{+2}$ was stable at $4 \mathrm{~min}$ for ascorbic acid and crud extract (CE), agreeing with data reported by Benzie and Strain (1996)[29]., whereas all the other assayed compounds showed a continues increment of absorbance and it even doubled their initial absorbance after $30 \mathrm{~min}$ of reaction[30]. All aerial part extracts of $C$. spinosa showed an antioxidant power higher than those of root part extracts $(\mathrm{P}<0.001)$ (Fig. $5 \mathrm{~A})$. In general the aerial part extracts had a ferric reducing ability greater than that of gallic acid at 4 and $30 \mathrm{~min}$ $(\mathrm{P}<0.001)$ (Fig. 6) which gave the strongest antioxidant activity compared with other standards by an $\mathrm{EC}_{1}$ value $(\mathrm{g} / \mathrm{l})$ of $(0.05 \pm 0.0005,0.037 \pm 0.0012)$ at 4 and $30 \mathrm{~min}(\mathrm{P}<0.01)$, respectively (Fig. 5B). whereas rutin had a ferric reducing ability lower than those of other standards with an $\mathrm{EC}_{1}$ value $(\mathrm{g} / \mathrm{l})$ of $(0.39 \pm 0.014,0.20 \pm 0.0003)$ at 4 and $30 \mathrm{~min}$ $(\mathrm{P}<0.01)$, respectively.
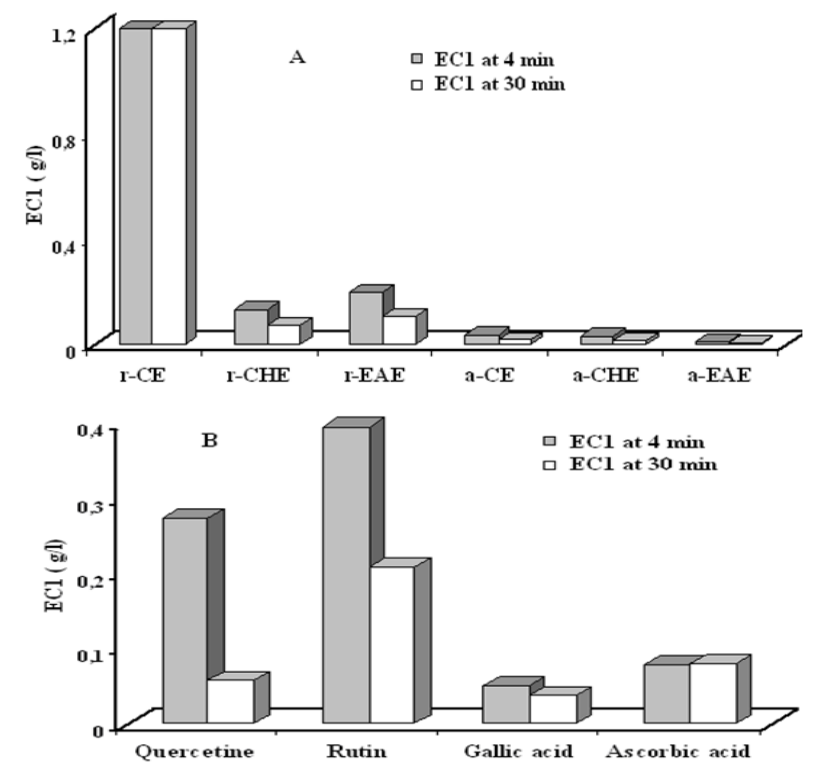

Figure 5. The antioxidant power of (A) root and aerial parts extracts of C. Spinosa and (B) standards. EC1 was the concentration of antioxidant having a ferric reducing ability equivalent to that $1 \mathrm{mM} \mathrm{FeSO}_{4} \cdot 7 \mathrm{H}_{2} \mathrm{O}$. a/r CE: aerial/root crud extract, $\mathrm{a} / \mathrm{r} \mathrm{CHE}$ : aerial/root chloroform extract, $\mathrm{a} / \mathrm{r}$ EAE: aerial/root ethyl acetate extract 
Plants compounds are an important source of active natural products which differ widely in terms of structure and biological properties. Phenolic compounds are commonly found in both edible and non-edible plants, and they have been reported to have multiple biological effects, including antioxidant activity[31].

The antioxidant activity of polyphenols can largely be predicted on the basis of their chemical structure. Antioxidant and antiradical activities of flavonoids are related to the presence of two neighboring hydroxyl groups on the B-ring, the number of free hydroxyl groups, a C2-C3 double bond in the C-ring, or the presence of a 3-hydroxyl group[46].

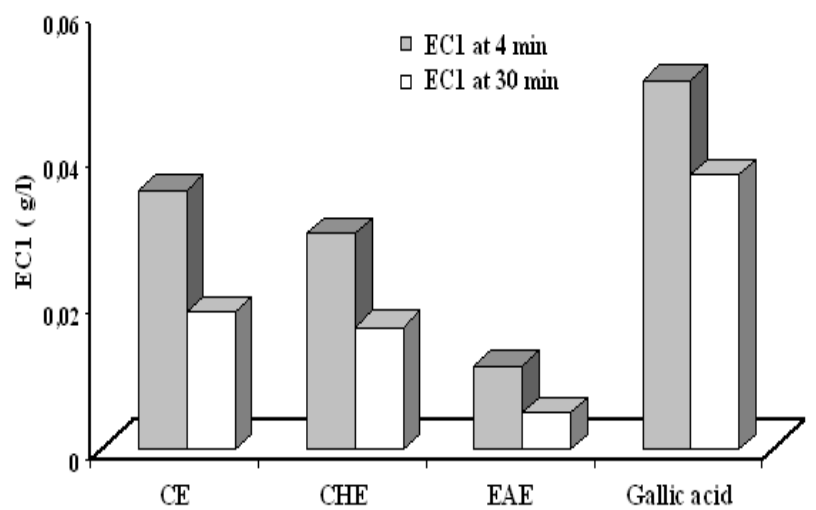

Figure 6. The antioxidant power of aerial part extracts compared with the gallic acid. CE; crud extract, CHE; chloroform extract, EAE; ethyl acetate extract

\section{Conclusions}

In conclusion, various antioxidant mechanisms action of the extracts in their antioxidant activity appeared to be identical, throughout the good correlation observed between different applied techniques. However, the magnitude of antioxidative potency varies with the type of extracts, which being related to the content in phenolic compounds and other yet to be discovered antioxidant compounds. These results are preliminary, it would be interesting to test the activity of high purified fractions and isolate the responsible molecules underlie the various detected activities in different extracts by more efficient methods.

\section{ACKNOWLEDGEMENTS}

This work was supported by the Algerian Ministry of Higher Education and Scientific Research (MERS) and by the Algerian Agency for the Development of Research in Health (ANDRS). We express our gratitude to these organisations.

\section{REFERENCES}

[1] Halliwell, B. 1995. How to characterize an antioxidant: an update. Biochem. Soc. Sym. 61: 73-101.

[2] Collin, A. R. 1999. Oxidative DNA damage, antioxidants, and cancer. Bio-Essays. 21: 238-246.

[3] Floyd, R. A. 1999. Antioxidants, oxidative stress, and degenerative neurological disorders. Proceedings of the Society for Experimental Biology and Medicine. 222: 236-245.

[4] Arti, R. V. Vijayakumar, M. Chandra, S. M. Chandana, V. R. 2009. In vitro and in vivo antioxidant properties of different fractions of Moringa oleifera leaves. Food and Chemical Toxicology. 47: 2196-2201

[5] Branien, A.L. 1975. Toxicoly and biochemistry of butylated hydroxyanisole and butylated hydroxytoluene. JAOCS. 52: 59-63.

[6] Silva, B. A. Ferreres, F. Malva, J. O. Dias, A. C. P. 2005. Phytochemical and antioxidant characterization of Hypericum perforatum alcoholic extracts. Food Chemistry. 90: $157-167$.

[7] Rivera, D. Inocencio, C. Ob'on, C. Alcaraz, F. 2003. Reviewof food and medicinal uses of Capparis L. subgenus Capparis (Capparidaceae). Economic Botany. 57: 515-534.

[8] Cooremans, B. 1999. An unexpected discovery in Medieval Bruges (Flanders,Belgium): seeds of the caper (Capparis spinosa L.). Environmental Archaeology. 4, 97-101.

[9] Afsharypuor, S. Jeiran, K.and Jazy, A. A. 1998. First investigation of the flavour profiles of leaf, ripe fruit and root of Capparis spinosa var. mucronifolia from Iran. Pharmaceutica Acta Helvetiae. 72, 307-309.

[10] Ali-Shtayeh, M. S. Abu Ghdeib, S. L. 1999. Antifungal activity of plant extracts against dermatophytes. Mycoses. 42, 665-672.

[11] Al-Said, M. S. Abdelsattar, E. A. Khalifa, S. I. El-feraly, F. S. 1988. Isolation and identification of an anti-inflammatory principle from Capparis spinosa. Pharmazie. 43, 640-641

[12] Eddouks, M. Lemhadri, A. Michel, J.B. 2005. Hypolipidemic activity of aqueous extract of Capparis spinosa L. in normal and diabetic rats. J. Ethnopharmacol. 98, 345-350.

[13] Baytop, P. 1984. Therapy with Medicinal Plants (Past and Present). Istanbul University Publications, Istanbul.

[14] Jacobson, R.L. Schlein, Y. 1999. Lectins and toxins in the plant diet of Phlebotomus papatasi (Diptera: Psychodidae) can kill Leishmania major promastigotes in the sandfly and in culture. Annals of Tropical Medicine and Parasitology. 93, 351-356.

[15] Gadgoli, C. Mishra, S.H. 1999. Antihepatotoxic activity of p-methoxy benzoic acid from Capparis spinosa. Journal of Ethnopharmacology. 66, 187-192.

[16] Trombetta, D. Occhiuto, F. Perri, D. Puglia, C. Santagati, N.A. De Pasquale, A. Saija, A. Bonina, F. 2005. Antiallergic and antihistaminic effect of two extracts of Capparis spinosa L. flowering buds. Phytotherapy Research.19 (1), 29-33.

[17] Markham, K. R. 1982. Techniques of flavonoid identification. Academic Press. London. 133p. Marnett, L. J. (2000) Oxyradicals and DNA damage. Carcinogenesis. 21: 361-370. 
[18] Cliffe, S. Fawer, M. S. Maier, G. Takata, K. Ritter, G. 1994. Enzyme assays for the phenolic content of natural juices. Journal of Agricultural and Food Chemistry. 42, 1824-1828.

[19] Bahorun, T. Gressier, B. Trotin, F. Brunete, C. Dine, T. Vasseur, J. Gazin, J. C. Pinkas, M. Luycky, M. Gazin, M. 1996. Oxygen species scavenging activity of phenolic extract from Hawthorn fresh plant organs and pharmaceutical preparation. Arzneim Forsch/Drug Res. 1-6.

[20] Baghiani, A. Arrar, L. Benboubetra, M. 2002. Purification and comparative kinetic study of the milk molybdoflavoenzyme, xanthine oxidoreductase, from different species. In "Chapman S., Perham R. Scrutton N. and Weber R. (Eds.), Flavins and flavoproteins 2002". Agency for Scientific Publications, Berlin. pp: 837-844.

[21] Baghiani, A. Harrison, R. Benboubetra, M. 2003. Purification and partial characterisation of camel milk xanthine oxidoreductase. Arch Physiol Biochem. 111: 407-414.

[22] Bray, R. C. 1975. Molybdenum iron-sulfer flavin hydroxylase and related enzymes. In: "The enzymes" 3ème Ed. Vol 12. PD Boyer Ed. Academic Press, New York. 299-419.

[23] Laemmli, U. K. 1970. Cleavage of structural proteins during the assembly of the head of bacteriophage T4. Nature. 227: 680-685

[24] Avis, P. G., Bergel, F., Bray, R. C., James, D. W. F. \& Shooter, K. V. 1956. Cellular constituent, the chemistry of xanthine oxidase. Part II. The homogeneity of crystalline metalloflavoproteine fraction. Journal of Chemical Society, 1212-1219

[25] Boumerfeg S, Baghiani A, Messaoudi D, Khennouf S \& Arrar L. 2009Antioxidant Properties and Xanthine Oxidase Inhibitory Effects of Tamus communis L. Root Extracts, Phytotherapy Research, 23, 283 - 288

[26] Robak, J. Gryglewski, R. J. 1988. Flavonoids are scavengers of superoxide anions. Biochem Pharmacol. 37. 837-841.

[27] Dapkevicius, A., Venskutonis, R., Van Beek, T. A., \& Linssen, P. H. 1998. Antioxidant activity of extracts obtained by different isolation procedures from some aromatic herbs grown in Lithuania. Journal of the Science of Food and Agriculture, 77, 140-146.

[28] Burits, M. and Bucar, F. (2000). Antioxidant activity of Nigella sativa essential oil. Phytotheraphy Research 14, 323-328.

[29] Benzie, I. F. F. Strain, J. J. 1996. The ferric reducing ability of plasma (FRAP) as a measure of "antioxidant power": The FRAP assay. Anal biochem. 239. 70-76.

[30] Pulido, R. Bravo, L. Saura-Calixto, F. 2000. Antioxidant activity of dietary polyphenols as determined by a modified ferric reducing/antioxidant power. J Agric Food Chem. 48. 3369-3402.

[31] Kahkonen, M. P. Hopia, A. I. Vuorela, H. J. Rauha, J. P. Pihlaja, K. Kujala, T. S. Heinonen, M. 1999. Antioxidant ac- tivity of plant extracts containing phenolic compounds. Journal of Agriculture and Food Chemistry 47. 3954-3962.

[32] Nakamura, M., Yamazaki, I. (1982) Preparation of bovine milk xanthine oxidase as a dehydrogenase form. The Journal of Biochemistry. 92: 1279-1286.

[33] Abadeh, S. Killacky, J. Benboubetra, M. Harrison, R. 1992. Purification and partial characterization of xanthine oxidase from human milk. Biochem Biophys Acta. 1117. 25-32.

[34] Benboubetra, M. Baghiani, A. Atmani, D. Harrison, H. 2004. Physicochemical and kinetic properties of purified sheep's milk xanthine oxidoreductase. J Dairy Sci. 87. 1580-1584.

[35] Castro, L and Freeman, B. A. 2001. Reactive oxygen species in human health and disease. Nutrition 17 . 161, 163-165.

[36] Koyama, K. Kaya, M. Ishigaki, T. Tsujita, J. Hori, S. Seino, T. Kasugai, A. 1999. Role of xanthine oxidase in delayed lipid peroxidation in rat liver induced by acute exhausting exercise. Eur. J. Appl. Physiol. 80: 28.

[37] Cao, G. Sofic, E. Prior, R. L. 1997. Free radic. Antioxidant and prooxidant behavior of flavonoids: Structure-activity relationships. Biologia Medica 22. 749-760.

[38] Montoro, P. Braca, A. Pizza, C. De Tommasi, N. 2005. Structure-antioxidant activity relationships of flavonoids isolated from different plant species. Food Chemistry. 92(2): $349-355$.

[39] McCord, J. M. Fridovich, I. 1968. The Reduction of Cytochrome c by Milk Xanthine Oxidase. The Journal of Biological Chemistry. 243 (21). 5753-5760.

[40] Rodrigo, M. Lazaro, M. J. Alvarruiz, A. Giner, V. 1992. Composition of capers (Capparis spinosa): influence of culivar, size and harvest date. J. Food Sci., 57, 1152-1154.

[41] Hall, C. A. and Cuppett, S. L. 1997. Structure-activities of natural antioxidants. In Auroma, O. I., \& Cuppett, S. L. (Eds.), Antioxidant methodology in vivo and in vitro concepts (pp. 141-170). Champaign, IL: AOCS Press.

[42] Nagai, T. Reiji, I. Hachiro, I. and Nobutaka, S. 2003. Preparation and antioxidant properties of water extract of propolis. Food Chemistry. 80, 29-33.

[43] Yang, J. H., Lin, H. C. and Mau, J. L. 2002. Antioxidant properties of several commercial mushrooms. Food Chemistry. 77, 229-235.

[44] Othman, A. Ismail, A. Abdul Ghani, N. Adenan, I. 2007. Antioxidant capacity and phenolic content of cocoa beans. Food Chemistry .100; 1523-1530.

[45] Heinonen, M. Lehtonen, P. J. and Hopla, A. 1998. Antioxidant activity of berry and fruit wines and liquor. Journal of Agricultural Food Chemistry. 48, 25-31.

[46] Rastija, V. Medic-Saric, M. 2008. QSAR study of antioxidant activity of wine polyphenols. European Journal of Medicinal Chemistry. 1-9. 